\title{
RULES OF NARRATIVE IN HUMAYUN'S TOMB
}

\author{
P. BANERJEE \\ School of Planning \& Architecture, India.
}

\begin{abstract}
Narrative essentially means story or storytelling. It is evident in all creative art forms like literature, painting, music, film and architecture. Narratives usually have a protagonist, one or more supporting characters and a setting.

Architecture tells stories through geometrical form, space, materials and by regulating the changing perspective along a designed motion path. Repeated visits to Humayun's Tomb in New Delhi revealed that the mausoleum has a story to tell. The narrative discussed here is based on the built environment that exists today as the site has undergone changes over the years. At the same time, there is no documentary evidence of what was consciously designed by the architect. The idea is to examine and establish the rules of the narrative so that one can use the tools and techniques of creating visual drama while designing.

Some of the rules identified in this research are as follows: (a) the tomb's massive white dome is alternatively revealed and hidden by the supporting characters, (b) glimpses of the protagonist are obtained through frames of arches, (c) the majestic protagonist is eventually revealed. The study attempts to show that a rapid rate of change of perspective with distance (visual acceleration) makes the visit interesting/dramatic. There is a direct relation between rate of change of horizontal and vertical angles of vision of a visitor and visual acceleration.
\end{abstract}

Keywords: char-bag, frame in a frame, Humayun's Tomb, narrative, prior indicator, visual drama.

\section{INTRODUCTION}

Narrative essentially means story or storytelling. It is evident in all creative art forms like literature, painting, music, film and architecture. Narratives usually have a protagonist, one or more supporting characters and a setting. The narrative, in architecture, is a spatiotemporal experiential process of revealing the protagonist in an interesting and dramatic way.

This article presents the narrative in the context of Humayun's Tomb (HT). The second Mughal emperor Humayun died in 1556. His widow Hamida Banu Begum appointed Mirak Mirza Ghiyath, a Persian architect, to build the tomb in 1569. It is the first distinct example of Mughal style inspired by Persian architecture [1].

The author has been working on Indo-Islamic architecture for two decades, using monuments as the primary evidence and for data collection. The first time when HT was visited long back on a Sunday evening, what struck the eyes was the huge white dome sitting right on the front gate named Bu Halima's (BH) gate. Though it was known that the dome is actually on the main tomb, the illusion was interesting and enjoyable. This motivated the author to go ahead down the paved way. The parking lot to the main tomb is quite long and one is likely to lose focus from HT while walking, but this did not happen. The narrative engaged the mind continuously by dramatically changing the visual field with a wide variety of architectural compositions. 
The following section narrates the experience of gradual disappearance and reappearance of the dome and a long axial view of a part of the well-lit façade of the tomb that grows bigger, brighter and clearer as one walks towards it. In the end, the majestic tomb, the protagonist, comes into full view through a grand arch. The first visit was exciting since a hidden story was unfolded.

When it was clear that a story exists in HT, a few friends were taken to the monument and the narrative was explained to them. This was repeated a number of times. The result was affirmative - they were convinced that a narrative existed.

Following that, a team was formed to carry out measured drawing, satellite image study and extensive photography to document the monument and re-examine the narrative.

The narrative discussed here is based on the built environment that exists today as the site has undergone changes over the years. At the same time, there is no documentary evidence of what was consciously designed by the architect and what was by default. The idea is that one understands and intellectually appreciates the existing experience [2], as well as learns and uses the rules of the narrative to create visual drama while designing. This article presents a part of the findings of the ongoing research.

\section{THE NARRATIVE}

Before reading the narrative of HT, it is important to understand the setting and characters of the story. The setting is a garden divided into four squares (char-bag) by water channels, as is the norm of any Mughal garden. This simulates paradise on earth, which is described as a square with two rivers flowing orthogonally along the centre lines and dividing the paradise into four parts. The river Yamuna used to flow right along its eastern boundary, but has now shifted course further eastwards. The protagonist of the narrative is obviously the tomb. The supporting characters include a high boundary wall and two grand gates, viz. $\mathrm{BH}$ gate and the west gate to the tomb complex (Fig. 1).

The key role of the protagonist is highlighted in a number of ways. First, it is placed at the crossing of the axes of symmetry of the char-bag, the focal point of the composition. This represents the centre of paradise. The axes are highlighted by water channels. Second, there is no other character in the visual field. Third, HT is the largest, highest and the most decorated building in the complex. It also has a dome on top, signifying its importance as a royal tomb.

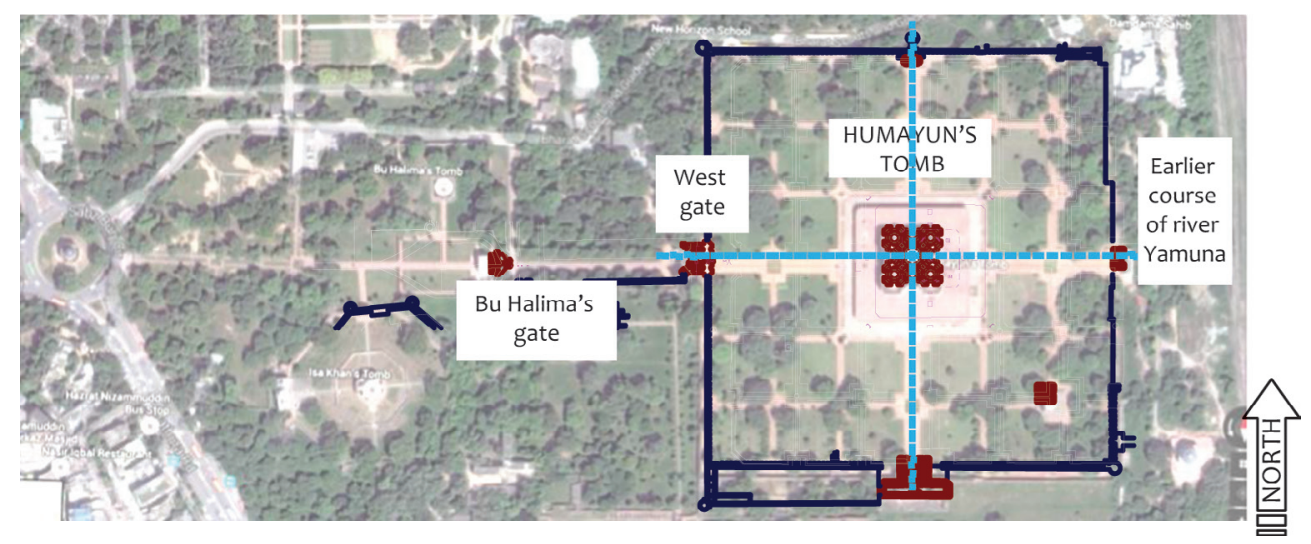

Figure 1: Site of HT. 


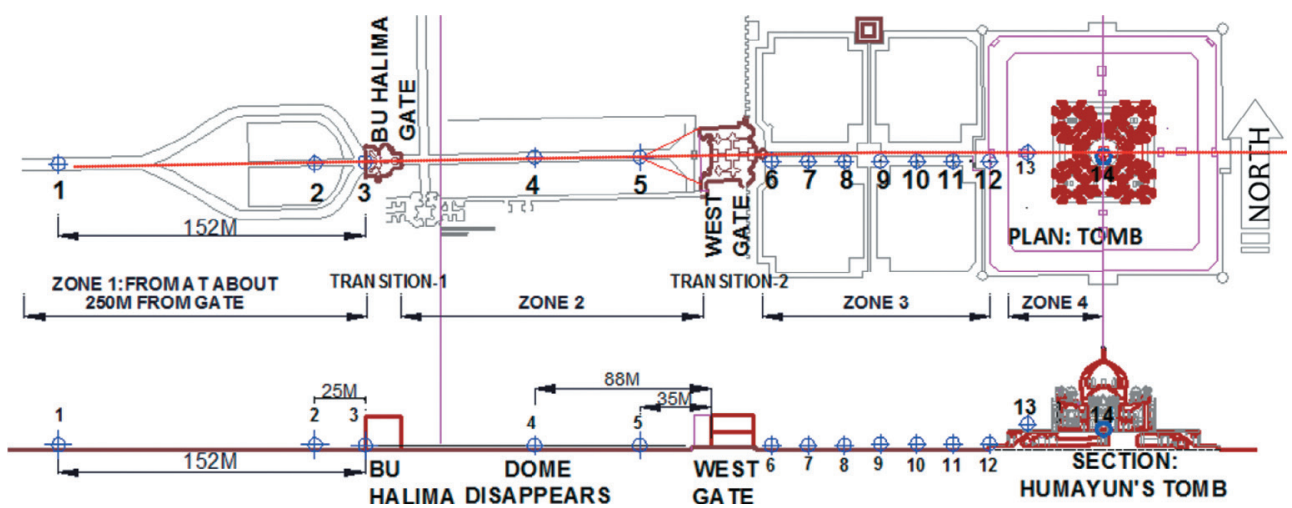

Figure 2: Plan and section of Humayun's Tomb, showing the observation points (1-14).

It may be interesting to note that the setting and the characters discussed are functional requirements of an Islamic tomb. As one moves through this architectural environment, a narrative begins to unfold. Any knowledgeable person can identify this after a couple of visits. Following is the narrative of HT. The points marked 1, 2, 3, etc. in the text below correspond to the points marked 1, 2, 3, etc. on the plan (Fig. 2).

1. The story begins at some point before the ticketing counter. One sees a double-storey building with a dome (Fig. 3, left), which drags one to the line of symmetry. This is the BH gate. The dome is a prior indicator of things to come.

As one moves towards the tomb, the dome gradually disappears behind this gate. The eye moves to the arched gateway (Fig. 3, middle). Fade in-fade out technique of storytelling in films is evident.

2. Through this arched gateway, one can see two brightly lit arches, alternating with contrasting dark arches, all along the same axis (Fig. 3, right). This contrast makes the bright
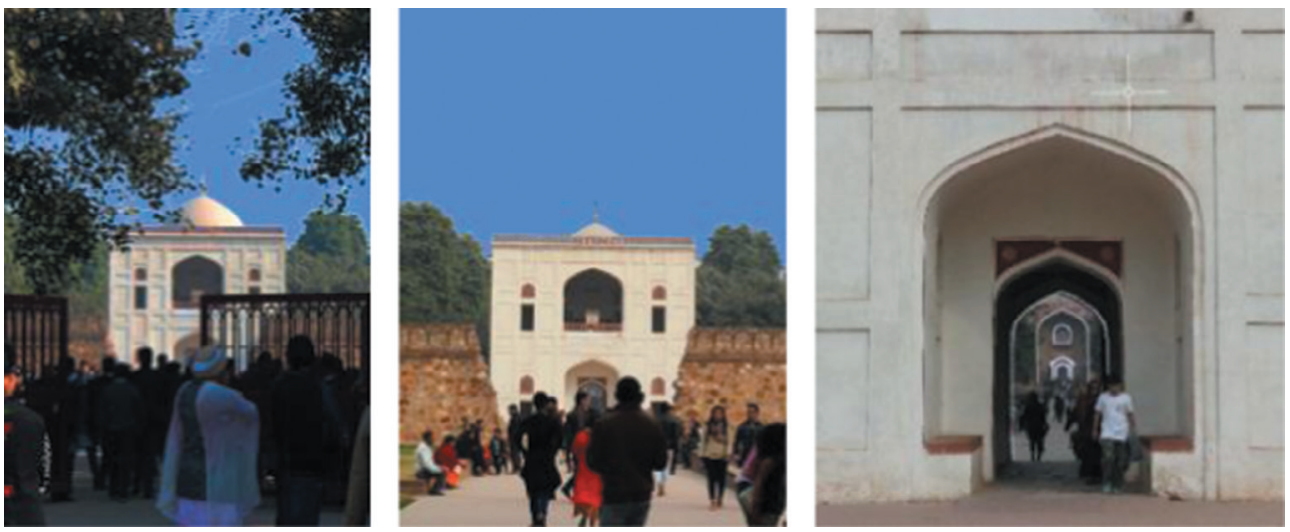

Figure 3: Dome seen above $\mathrm{BH}$ gate (left), dome gradually disappearing behind $\mathrm{BH}$ gate (middle), series of arches seen through $\mathrm{BH}$ gate (right). 
planes more prominent. The arches use a frame-in-a-frame concept to draw the focus to the innermost arch, which seems important. This is the west gate of the HT complex.

3-4. Very close to the BH gate, one can distinctly see the west gate beyond it, with a dome on top (Fig. 4, left). As one crosses the former and moves ahead, the dome gradually disappears and the attention moves to the entrance arch of the west gate (Fig. 4, middle and right). Repeated use of the same techniques, viz. prior indicator and fade in-fade out, once again highlights the protagonist.

5. As one approaches the west gate of HT, one gets glimpses of a brightly lit space with a majestic building beyond (Fig. 5, left). It is easily identified as the HT. Interesting to note is the hierarchy of importance - HT is grander than the west gate, which in turn is bigger and more decorative than the $\mathrm{BH}$ gate.

Inside the west gate: As one moves inside the west gate, the majestic HT can be seen (Fig. 5 , middle). The tomb appears to be a two-dimensional object right next to this gate. This is an illusion. The sense of depth does not work as one is in the relatively darker space of the gateway and the pupils are dilated.
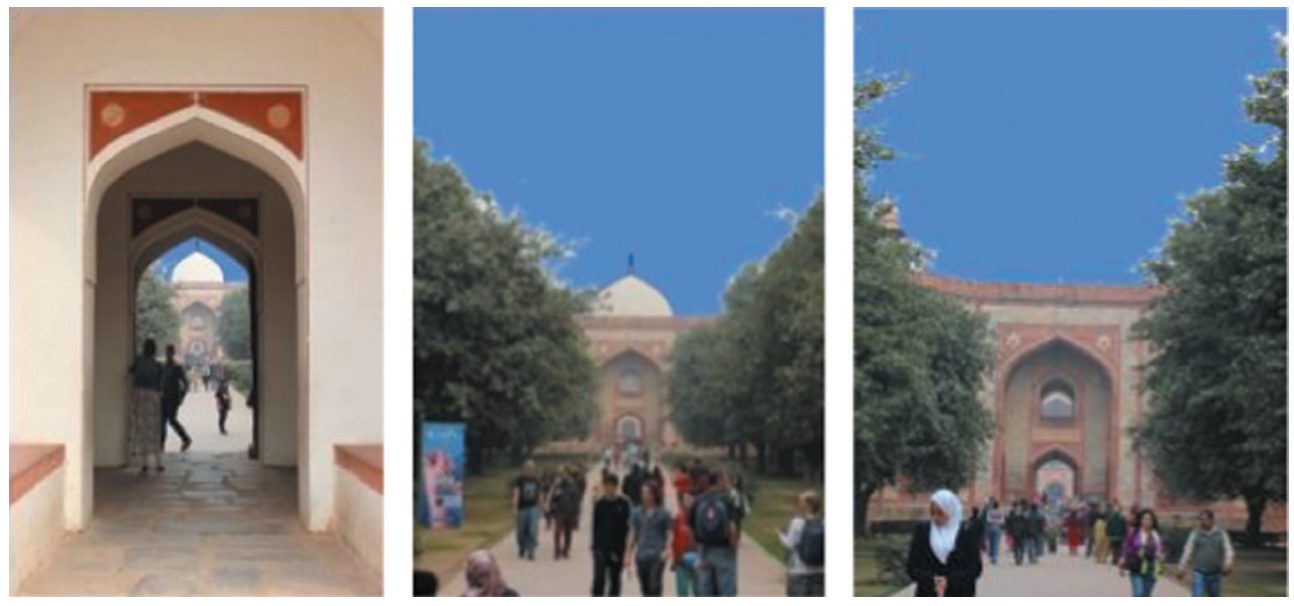

Figure 4: Dome seen on west gate, through $\mathrm{BH}$ gate (left), dome gradually disappearing behind west gate (middle), HT seen through west gate (right).
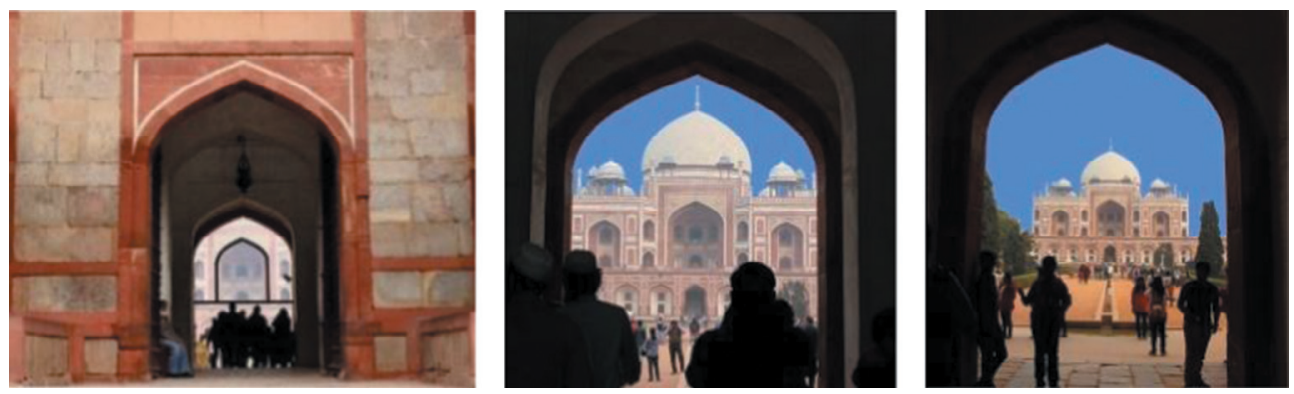

Figure 5: Arch of HT seen through west gate (left), HT appears right next to west gate (middle), HT framed by west gate (right). 


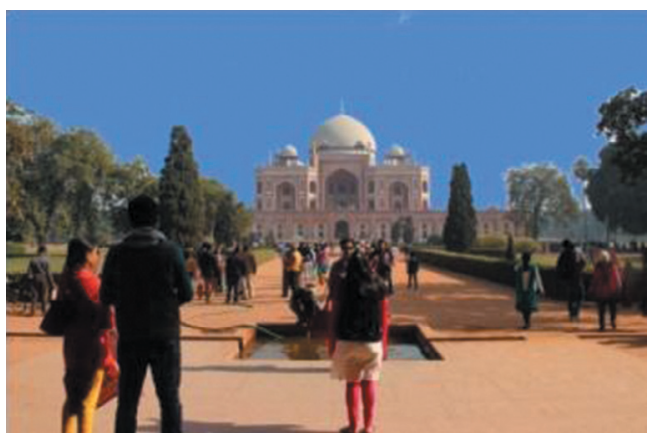

Figure 6: Majestic HT stands against the blue sky.

As one moves through the gate, one sees the whole building beautifully framed by the arched gateway (Fig. 5, right). The monument seems to have retracted back and one comprehends that it is not so close after all. This happens when one moves through the gate to the light on the other side. The pupils narrow down and the sense of depth returns. As one moves outside into the open bright space, the entire mausoleum can be seen (Fig. 6). Its grandness and dignity stun one and all.

6-12. The path now moves away from the axis in a composition that has been axially symmetric till now, due to the water channels that run along the axes.

As one moves along the asymmetric path, the view is slightly asymmetric, initially hardly noticeable (Fig. 7, left). The rate of change of perspective with distance (visual acceleration) increases fast towards the end of the path and the building appears overpowering (Fig. 7, middle). One no longer perceives the proportioning system. The dome is barely visible. A person moves back to the axis at this point and proceeds towards the axially placed stairs of the tomb (Fig. 7, right). Moving back to the axis does not reduce this feeling of being overpowered by the monument.

13. The stairs rise to the podium along the axis of the building (Fig. 8, left). The stairwell has walls on both sides. It is a semi-dark space. As one climbs, the view is cut off, except glimpses of the HT if one looks up. So, when one emerges on the wide, bright podium with the mausoleum so big and close and accessible right in front, one feels a sense of surprise. This is a sharp cut in the narrative and the contrasting experience before and after the flight of steps (e.g. semi-dark to bright, confined narrow view to unrestricted view, inaccessible monument on a podium to access in front) highlights this narrative technique.
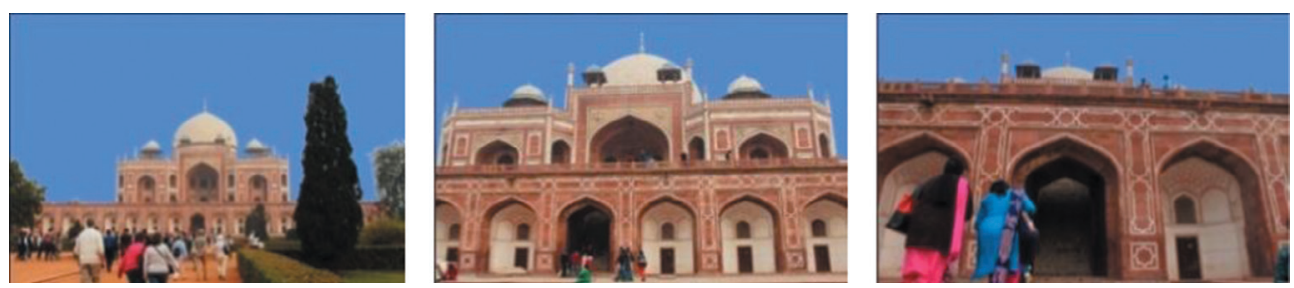

Figure 7: The asymmetric view is hardly noticeable (left), but HT appears overpowering towards the end of the path (middle and right). 

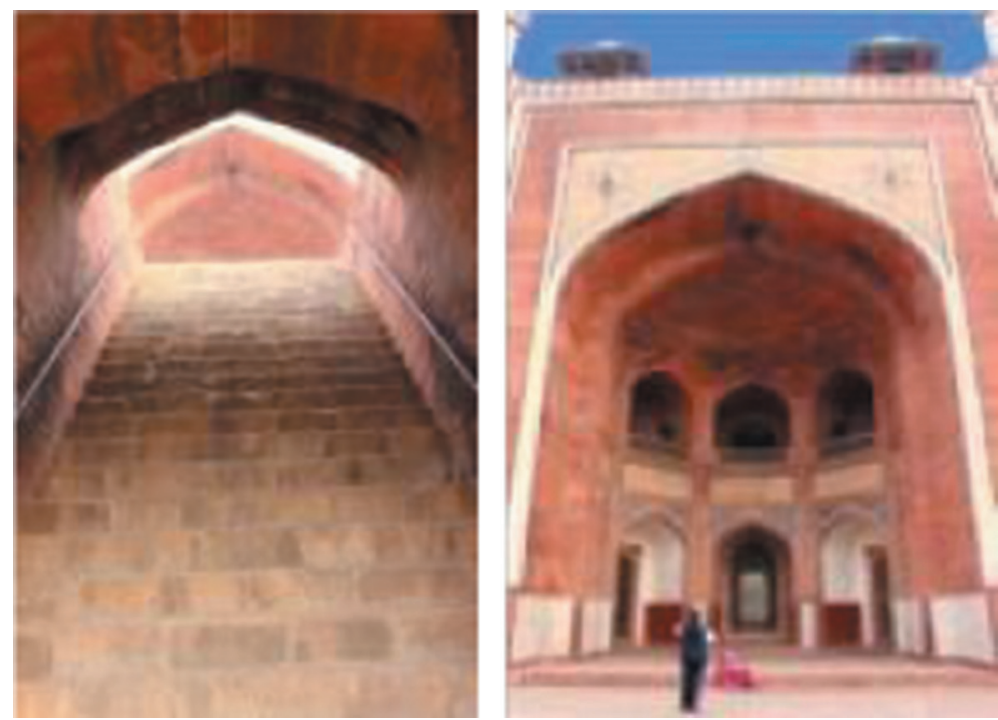

Figure 8: The axial stairs to the HT podium (left), only the arched gateway seen from the podium (right).

At this close proximity, the building goes beyond the comfortable cone of vision, and the focus shifts to the entrance arch (Fig. 8, right). It may be interesting to note that this arch, which appeared to be only a part of the composition earlier, is now perceived as the main element in the visual field.

The narrative journey now has a twist, literally. One expects an axial entry. But the arched gateway in front is blocked with a jaali, disappointing the expectation of a visitor. This is the west side of the tomb and functional requirements demand a mosque or a mihrab, not an entry. But, where is the mosque?

14. The visitor has to go around the tomb (Fig. 9) and enter through the doorway on its southern façade (Fig. 10, left). As one enters the main tomb chamber, stands in front of the

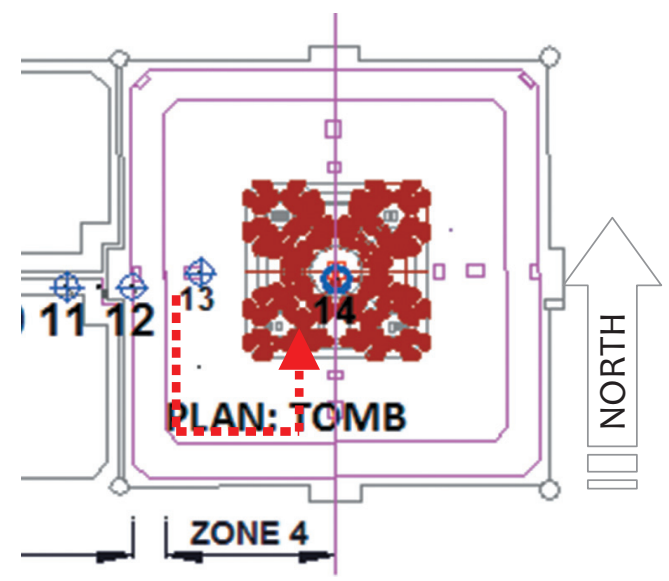

Figure 9: A visitor has to move to the southern entry to HT. 

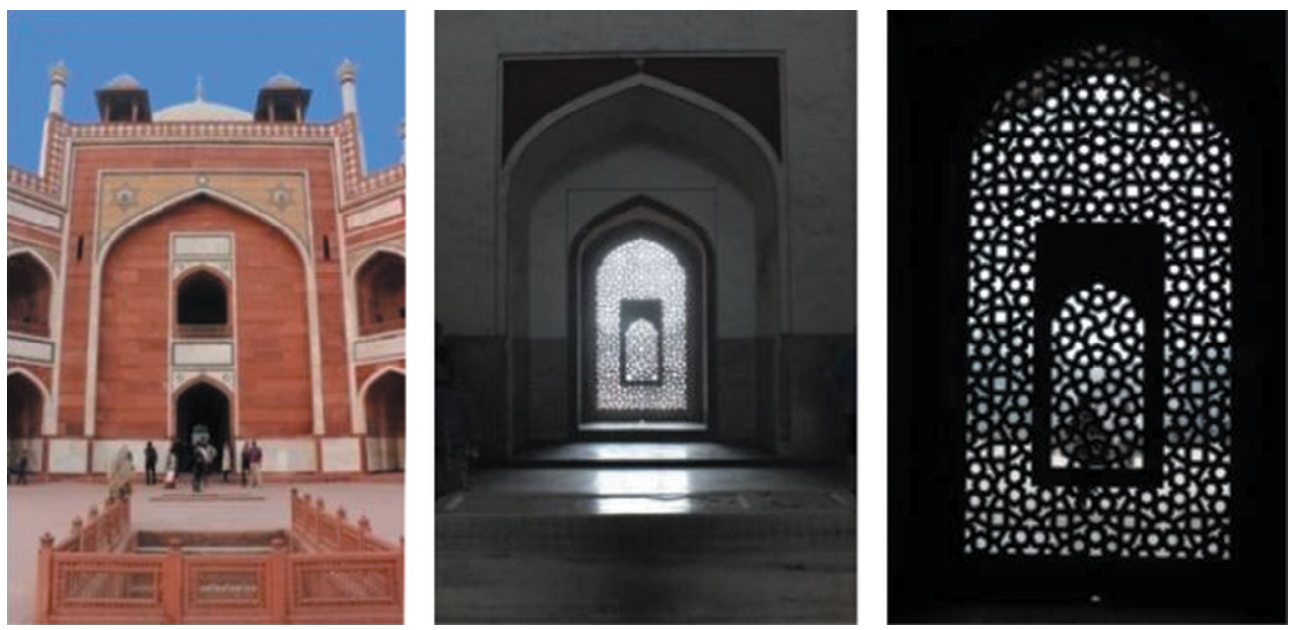

Figure 10: South gate of HT (left), quibla on the west wall (middle and right).

cenotaph and looks left, one sees the quibla symbol sculpted in the jaali on the west wall exquisite, beautiful and subtle (Fig. 10, middle and right). That is where the narration ends.

Thus, the underlying rules revealed by the detailed study of the narrative of the HT are prior indicator, frame in a frame, hierarchy of importance, fade in-fade out, illusion, visual acceleration, sharp cut, use of contrasts and beating expectations.

\section{ANALYSIS}

The narrative in this article shows that the interest of the visitor has been kept alive after crossing the west gate by regulating the rate of change of perspective of HT in a dramatic manner. Let us understand the parameters involved in such experience in a quasi-analytical way.

Based on extensive field surveys, five parameters (there may be some more) have been identified that regulate the rate of change of perspective, viz. (a) distance from the west gate to the tomb, (b) eccentricity of the line of movement of the observer with reference to the symmetrical axis of the building (angle $\alpha$ ), (c) horizontal angle of vision of the visitor (angle $\beta$ ), (d) vertical angle of vision of the visitor (angle $\gamma$ ), (e) building form, shape, solid, void, reflecting surface, etc. Parameters 'a' and 'e' are relevant when a comparative analysis is made with similar monuments such as Taj Mahal, Itmad-ud-daula and Safdarjung Tomb. Hence, for HT, the parameters b (angle $\alpha$ ), c (angle $\beta$ ), d (angle $\gamma$ ) have been considered (Fig. 11). Based on extensive field study once again, it may be proposed that, as $\alpha$ and/or $\beta$ and/or $\gamma$ varies, the rate of change of perspective will be different, inducing interest of the visitor. If all three change simultaneously, the effect on the visitor will be dramatic.

The narrative can now be analysed in terms of these parameters. In this article, the narrative of HT has been divided into four parts (Fig. 12): zone 1 - Before one reaches BH gate; zone 2 - $\mathrm{BH}$ gate to the west gate; zone 3 - west gate to the podium, zone 4 - the podium to the tomb chamber. In each of these zones, the building in front has been analysed with respect to the three parameters $\alpha, \beta, \gamma$. 


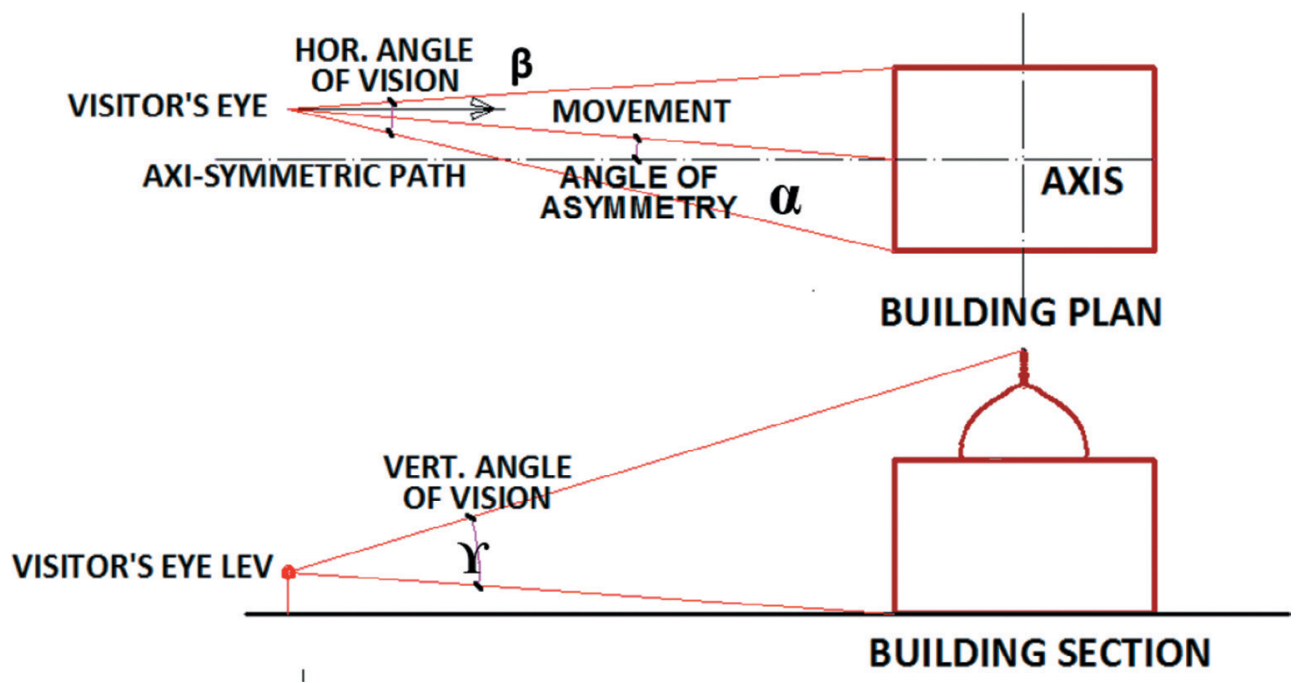

Figure 11: Diagrammatic representation of $\alpha, \beta, \gamma$.

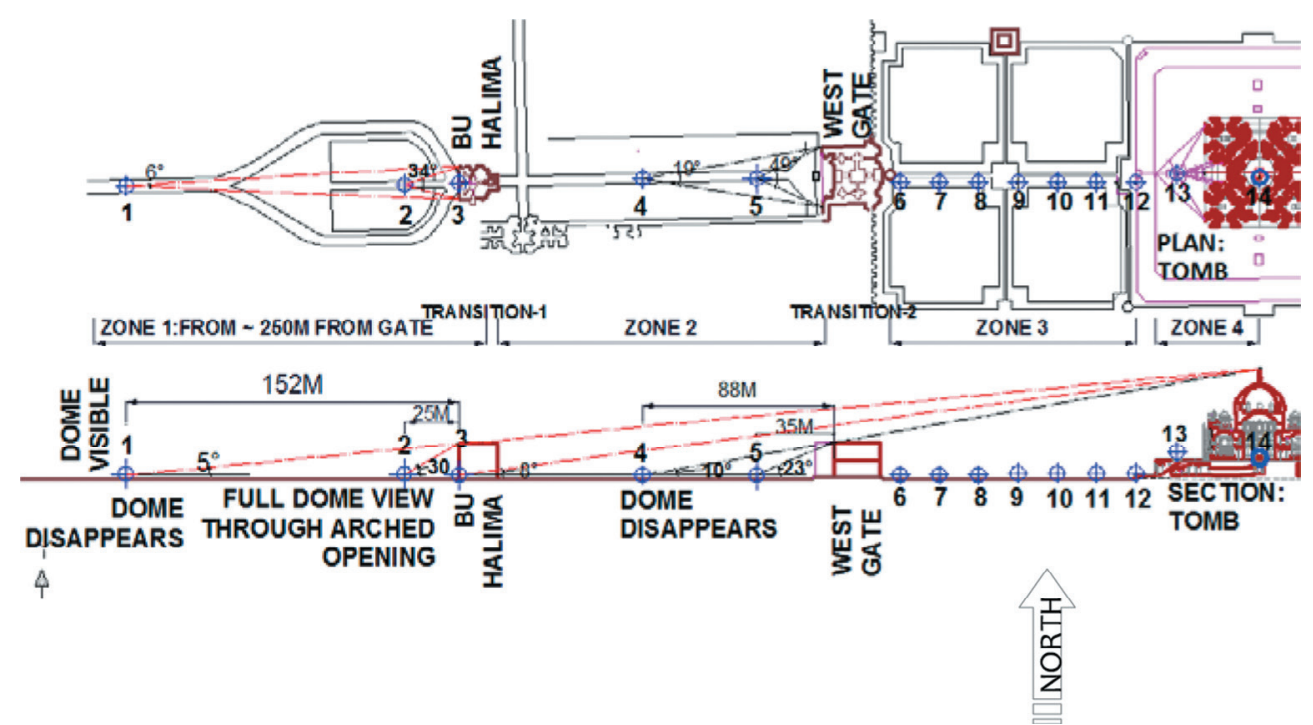

Figure 12: Zones of the narrative.

\subsection{Zone 1: from $250 \mathrm{~m}$ to $\mathrm{BH}$ gate (refer Fig. 3)}

This starts at about $250 \mathrm{~m}$ from $\mathrm{BH}$ gate, where the visual composition of the dome on the building is easily comprehensible. Most of the visitors respond spontaneously to that (Fig. 12). As one walks, the dome starts sinking and disappears at point 1 (about $152 \mathrm{~m}$ from the gate). The eye shifts from the top of the gate to its façade. At point 2 (about $25 \mathrm{~m}$ from the gate), the facade becomes visually incomprehensible and the eye shifts further down to 
the doorway of the $\mathrm{BH}$ gate. The full view of the west gate with a huge white dome appears through the arched opening. In order to understand why such changes of perception occur, pictures were clicked from points $1,2,3$. The photos recorded what the eyes had seen, so that the experience might be shared with a wider audience. Then, drawings were made and the angles $\alpha, \beta, \gamma$ were calculated with respect to $\mathrm{BH}$ gate. The horizontal and vertical angles $(\beta$, $\gamma$ ) changed significantly from point 1 to point 2 . Low $\beta$ and $\gamma$ corresponds with easy visual comprehension, while their higher values relate to visual incomprehension (Table 1). This leads the eye to the arched opening of the gate (point 3 ).

\subsection{Zone 2: BH to west gate (refer Figs. 4-6)}

As one walks from point 3, through $\mathrm{BH}$ gate and forward, the dome starts sinking again (Fig. 12). It disappears completely at point 4 ( $88 \mathrm{~m}$ from west gate). The experience of zone 1 repeats itself. The eye shifts from the top of the gate to its façade. At point 5 (about $35 \mathrm{~m}$ from the west gate), the facade becomes visually incomprehensible and the eye shifts further down to the doorway of the west gate. A part of the well-lit tomb façade can be seen through the relatively dark interior of the west gate.

As in zone 1 , pictures were clicked and $\alpha, \beta, \gamma$ calculated with respect to the west gate. The horizontal and vertical angle $(\beta, \gamma)$ changed significantly from point 3 to point 5 . Once again, low $\beta, \gamma$ corresponds to easy visual comprehension at point 3 , while higher values relate to visual incomprehension (Table 2), as at point 5 . This leads the eye to the arched opening of the gate (point 5). Thus ends the analysis of zone 2.

Superimposing the analysis of zones 1 and 2 (Tables 1 and 2), it is seen that when the horizontal and/or vertical angle is more than about $25^{\circ}$, the perception becomes increasingly incomprehensible and the eye looks for any object which is within this angle. This angle relates to the cone of vision of the human eye [3].

\subsection{West gate to the podium (refer Figs. 7 and 8)}

As one crosses the west gate, the full view of the protagonist appears. The challenge here is to retain a visitor's interest while approaching the tomb over a long distance. An axially

Table 1: Comparison of $\alpha, \beta, \gamma$ at points 1 and 2.

\begin{tabular}{cllll}
\hline & $\alpha$ & $\beta$ & $\gamma$ & Remarks \\
\hline 1 & 0 & 6 & 5 & Shallow angle, visually comprehensible \\
2 & 0 & 34 & 30 & Steep angle, visually incomprehensible \\
\hline
\end{tabular}

Table 2: Comparison of $\alpha, \beta, \gamma$ at points $3,4,5$

\begin{tabular}{lllll}
\hline & $\alpha$ & $\beta$ & $\gamma$ & \multicolumn{1}{c}{ Remarks } \\
\hline 3 & 0 & 12 & 8 & Shallow angle, visually comprehensible \\
4 & 0 & 19 & 10 & Shallow angle, visually comprehensible \\
5 & 0 & 49 & 23 & Steep angle, visually incomprehensible \\
\hline
\end{tabular}


symmetrical $(\alpha=0)$ approach might have been rather boring. The central waterway constrains one to leave the line of symmetry. The rate of change of view of the tomb with distance increases due to this asymmetric approach - slow in the beginning and significantly fast as one reaches close to the tomb, making the final lap of journey interesting. All this is related to the rate of change of $\alpha, \beta$ and $\gamma$.

$\alpha, \beta$ and $\gamma$ have been calculated from the measured drawing. The length from the west gate to the podium has been divided into six equal parts, each $18 \mathrm{~m}$, for calculating $\alpha, \beta$ and $\gamma$. Photographs have also been clicked from these points to examine whether the actual experience of changing views of the tomb tally with the rate of change of these three angles with distance. $\beta$ has been calculated considering the tomb-width, as it dominates the visual field. The angles of asymmetry, horizontal and the vertical have been measured (Fig. 13).
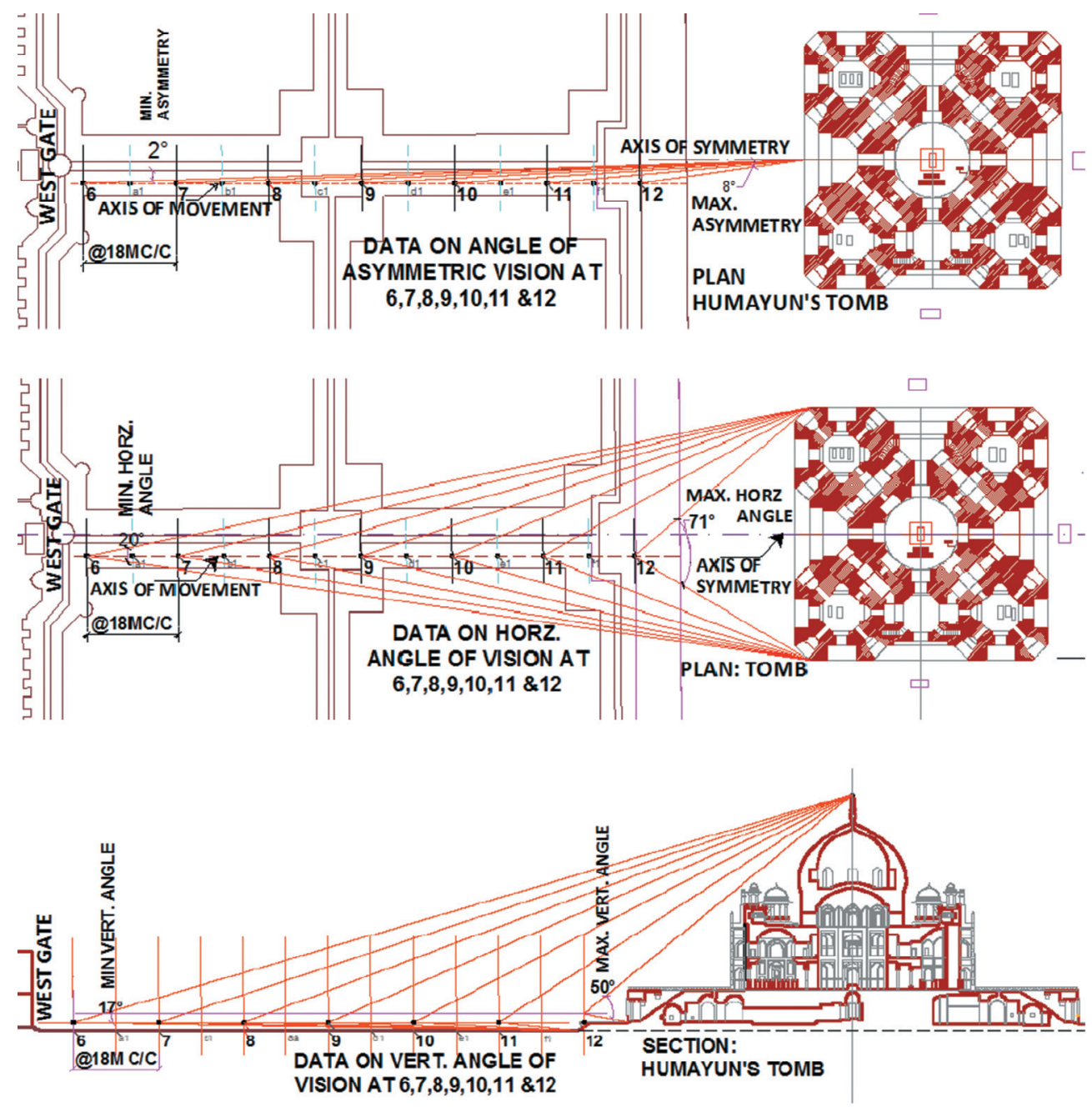

Figure 13: Angles $\alpha, \beta, \gamma$ calculated from measured drawings. 
Figure 14 shows the change in the three angles $(\alpha, \beta, \gamma)$ from points 6 to 12 . It also shows the one-to-one correspondence between the photos of the tomb and $\alpha, \beta$ and $\gamma$ at these points. The variation of $\alpha, \beta, \gamma$ is less from points 6 to 9 (Fig. 14). Thereafter, $\beta$ and $\gamma$ change fast. The photos (Fig. 14) also show that there are significant changes in view at points 10,11 and 12 , corresponding with proportionate changes in $\beta$ and $\gamma$.

It may be interesting to note that at point 9, the horizontal and vertical angles are more than $25^{\circ}$, thus corresponding to the finding from zones 1 and 2 . The HT becomes increasingly overpowering from this point.

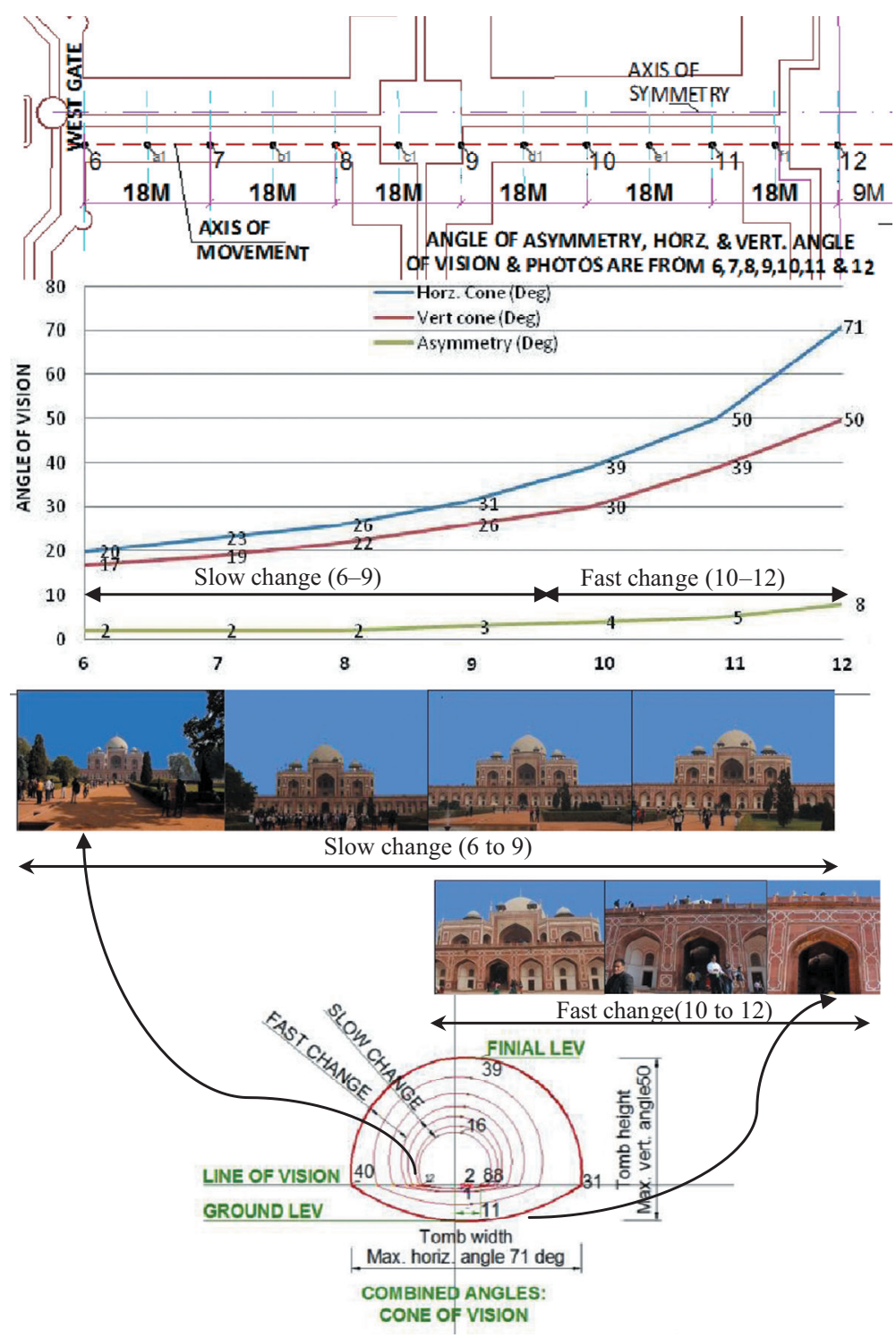

Figure 14: Part plan of HT; change in the angles $\alpha, \beta, \gamma$ from points 6-12; photographs corresponding to points $6-12$; combined $\beta, \gamma$ graph. 
Figure 14 (lower end) combines $\alpha, \beta, \gamma$ in a single diagram, which represents how the HT relates to the actual cone of vision of an observer as one moves towards the tomb. The closer curves signify slow change in perspective and the rarefied ones indicate fast change. The arrows correlate the curves and the photos. This combined graph also shows that there is a direct relation between the change in $\alpha, \beta, \gamma$ and the actual experience of changing perspective.

\subsection{Zone 4: Podium to the Tomb chamber (refer Fig. 10)}

At the podium, in front of the stairs, one does not comprehend the whole building. The corresponding horizontal angle $\beta$ is $120^{\circ}$ and vertical angle $\gamma$ is $61^{\circ}$. Based on the analysis and learning from zones 1, 2 and 3, one understands that the building appears incomprehensible as $\beta$ and $\gamma$ are much beyond $25^{\circ}$.

This section shows that the rate of change of perspective with distance tallies with the rate of change of $\alpha, \beta$ and $\gamma$. Fast change in these angles results in a dramatic effect.

\section{CONCLUSION}

The story that began with a casual visit to HT led to the present research and has now gathered adequate evidence in favour of a narrative in HT. In this narrative, it is obvious that the tomb is the protagonist. However, the way this obvious fact has been revealed by creating a drama of exposing and hiding the protagonist with the help of two gates is unprecedented. HT is without a predecessor in India.

The four zones of narration have been based on the underlying techniques/rules such as prior indicator, use of contrasts, frame in a frame, hierarchy of importance, visual acceleration, etc. The transition between two narrative zones happens by fade in-fade out or sharp cut.

The visual acceleration, i.e. rate of change of the building's views with movement, is found to be proportional to the combined effect of changing horizontal and vertical angles of vision. The analysis shows that the asymmetrical, horizontal and vertical angles of vision are very important for perception. The latter two, forming the cone of vision, need to be within $25^{\circ}$ for visual comprehension. However, this is an interdisciplinary research with other functional specialists and in the near future more concrete results are expected to come up in this context.

We generally appreciate Islamic architecture, conserve it and develop awareness about it. However, we forget that many of the timeless qualities of our Islamic heritage are relevant even today. The findings of this article may be used as a design tool and to predict the response of people to a heritage building and site.

\section{REFERENCES}

[1] Archaeological Survey of India, Government of India, available at http://asi.nic.in/asi_ monu_whs_humayuntomb.asp, 2011 (accessed 3 January 2016).

[2] Jacob, B., The Visionary Eye, The MIT Press: Cambridge, MA, 1981.

[3] Bob, J., Does a $50 \mathrm{~mm}$ equivalent lens really see the same as a human, available at http://www.earthboundlight.com/phototips/normal-lens-vs-human-vision.html, 2013 (accessed 3 January 2016). 